\title{
Assessment of the Water Quality in the Ariake Sea Using Principal Component Analysis
}

\author{
Toshinori Tabata ${ }^{1}$, Kazuaki Hiramatsu ${ }^{2}$, Masayoshi Harada ${ }^{2}$ \\ ${ }^{1}$ Department of Agro-Environmental Sciences, Graduate School of Bioresource and Bioenvironmental Sciences, \\ Kyushu University, Fukuoka, Japan \\ ${ }^{2}$ Department of Agro-Environmental Sciences, Faculty of Agriculture, Kyushu University, Fukuoka, Japan \\ Email: t.tabata.1232@gmail.com
}

Received 21 December 2014; accepted 2 January 2015; published 14 January 2015

Copyright (C) 2015 by authors and Scientific Research Publishing Inc.

This work is licensed under the Creative Commons Attribution International License (CC BY).

http://creativecommons.org/licenses/by/4.0/

(c) (i) Open Access

\begin{abstract}
The aim of this study is to investigate the condition of the Ariake Sea, Japan, which has been suffering from severe environmental issues for the past few decades. Water quality data have been generated from several points in this area for over 30 years by the Fukuoka, Saga, Kumamoto, and Nagasaki prefectures. In order to understand the characteristics of this sea, principal component analysis (PCA) was utilized using 11 water quality parameters; transparency, temperature, salinity, dissolved oxygen (DO), chemical oxygen demand (COD), dissolved inorganic nitrogen (DIN), ammonium-nitrogen $\left(\mathrm{NH}_{4}^{+}-\mathrm{N}\right)$, nitrate-nitrogen $\left(\mathrm{NO}_{3}^{-}-\mathrm{N}\right)$, nitrite-nitrogen $\left(\mathrm{NO}_{2}^{-}-\mathrm{N}\right)$, phosphatephosphorus, ( $\left.\mathrm{PO}_{4}^{3-}-\mathrm{P}\right)$ and silica. PCA conveyed the amount of nutrients originating from the river, the organic pollution level, and seasonal changes. Subsequently, principal component scores were calculated for each point. It was concluded that the Ariake Sea environment has been affected by two main factors, which are the nutrients from the Chikugo River and anticlockwise tidal residual flow. These two factors must be considered for the environmental restoration of the Ariake Sea.
\end{abstract}

\section{Keywords}

Ariake Sea, Principal Component Analysis, Nutrients, Anticlockwise Tidal Residual Flow

\section{Introduction}

The Ariake Sea is a semi-closed bay located in the Kyushu Island, Japan (Figure 1). It is surrounded by the Fukuoka, Saga, Nagasaki, and Kumamoto prefectures and is the biggest bay in the Kyushu Island. Vast quantities 


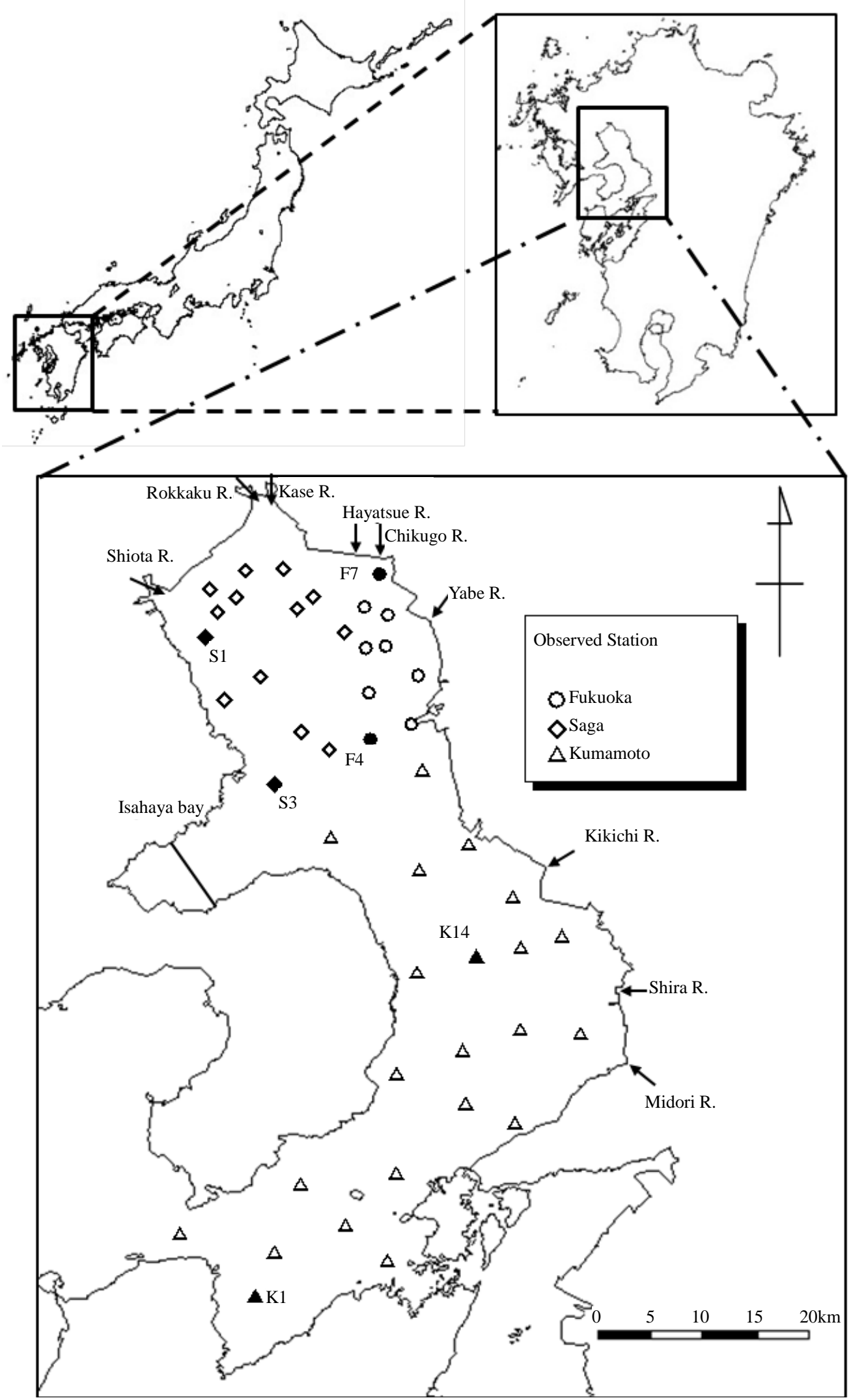

Figure 1. Location of the Ariake Sea, river inflow, and the observation station by coastal prefectures. 
of nutrients flow into the sea, and due to its shape the retention period is long. Hence, the Ariake Sea is a homeostatic eutrophic area. Typically, eutrophic areas tend to suffer from the formation of red tides or the appearance of anoxic water mass leading to a decrease of fish production. However, owing to its unique character, the Ariake Sea has not suffered from any of these issues. In fact, seaweed (Nori) aquafarming has been increasing in the Ariake Sea, currently accounting for $40 \%$ of the Nori production in Japan. Moreover, because there are large areas of tidal flats $\left(>200 \mathrm{~km}^{2}\right)$, many bivalves inhabit this area; in turn, the Ariake Seahas been renowned for bivalve production. Thus, the Ariake Sea was known for its high biological productivity.

Previously, the Ariake Sea has not suffered from environmental issues, despite the eutrophic nature of the area. However, its environmental deterioration is becoming a serious social problem with the recent occurrence of large red tides. Since 1985, the number of red tide outbreaks has exceeded 20/year. During the period 19982002, red tides occurred $>30$ year. Furthermore, numerous studies have been conducted on large anoxic water mass, which has also become a serious issue in the Ariake Sea [1]-[3].

More recently, fish conservation has been required in the Ariake Sea. The destabilization of Nori products has also become a serious problem in recent years. The average production value was 20.8 billion yen/year during the period 1978 to 1989. After 1990, the production value varied from 13.1 billion to 23 billion yen/year with few years exceeded the 20 billion yen/year level [4]. Catches of bivalves have been drastically decreasing. The catch of bivalves in the Ariake Sea was 70,000 to 110,000 tons/year during the late 1970s and early 1980s. These values decreased to 50,000 tons/year in 1984 and dropped below 20,000 tons/year in 1998. Now, the catch of bivalves is $1 / 10$ the value during its peak period [5].

Finding a solution for these issues has become an urgent issue. Thereby, many surveys have been conducted in this area with the purpose of environmental improvement. For instance, the mechanisms of the outbreak of red tides were reported [6]. Continuous measurements have been carried out to elucidate the process of red tides and the formation of oxygen deficient water [7]. In addition, many researchers have constructed numerical models and analyzed the mechanisms of the environmental phenomena [8]-[10]. However, despite the many studies on the environmental condition of the Ariake Sea, the situation has not improved yet.

Recently, methods using multidimensional data analysis are used in environmental studies. Principal component analysis (PCA) is one of the multidimensional data analysis methods that facilitate the interpretation of complex data matrices to better understand water quality and ecological status. It has been used for a number of water-quality improvement related assessments [11]-[13]. This method is especially effective when a substantial quantity of data have been collected for the target area.

The prefectures along the Ariake Sea coast (Fukuoka, Saga, Nagasaki, and Kumamoto) have been surveying more than 10 water quality indicators for over 30 years in a number of stations. Therefore, enormous amounts of data have been stored for this area. However, there few studies have used multidimensional data analysis for the water quality assessment in this area. In this study, enormous quantities of data were analyzed using PCA in order to study the environmental condition of the Ariake Sea.

\section{Materials and Methods}

\subsection{Description of the Study Area}

The Ariake Sea is a typical semi-enclosed inner bay located in the Kyushu Island, Japan (Figure 1). It has an area of $170 \mathrm{~km}^{2}$, an average depth of $20 \mathrm{~m}$, and a volume of 34 billion $\mathrm{m}^{3}$. Many rivers flow into the Ariake Sea, namely the Chikugo, Shiota, Rokkaku, Kikuchi, Yabe, Mdori, and Shira. The annual volume of freshwater inflow is about $8 \times 10^{9} \mathrm{~m}^{3}$. The Chikugo River is the largest river flowing into the Ariake Sea and its inflow amount accounts for $50 \%$ of the overall freshwater inflow. The area of the Ariake Sea is large compared with its depth and width, and its mouth at Kuchinotsu is narrow. Because of this, the oscillation period of the inner bay of the Ariake Sea resonates with the semidiurnal tide in the outer sea [14]. Thus, the Ariake Sea has the largest tidal range in Japan, reaching up to $6 \mathrm{~m}$. Given that the tidal range is so large, over $200 \mathrm{~km}^{2}$ of tidal flats emerge at the spring ebb tide.

As mentioned previously, the water quality of the Ariake Sea has been measured by prefectures along its coast (Fukuoka, Saga, and Kumamotos) at several stations (Figure 1). Figure 2 shows the survey results of station F1 from April 1997 to March 2013. Table 1 shows the data provided by the coastal prefectures in the Ariake Sea. 


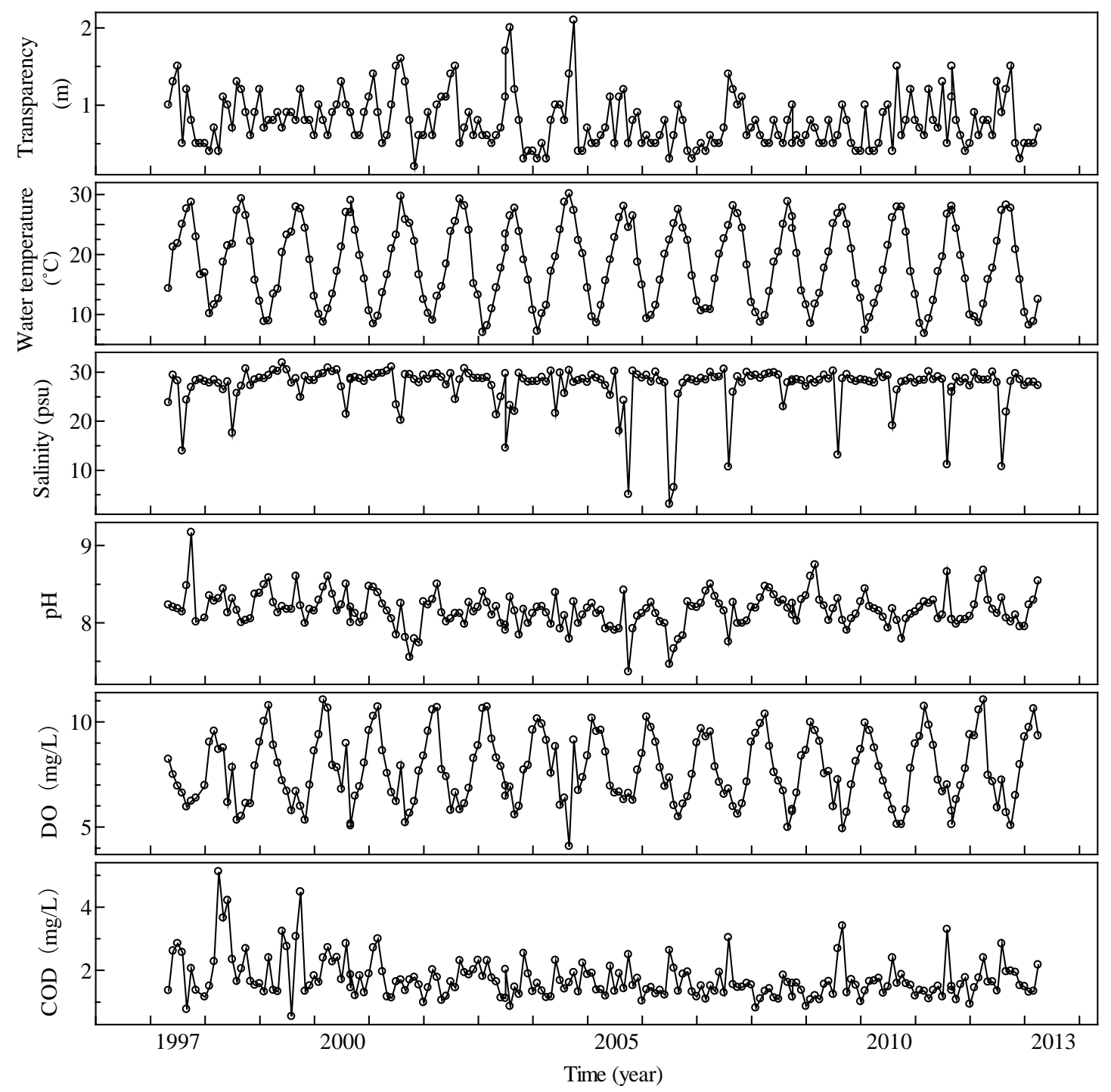

Figure 2. Results of the surveys from April 1997 to March 2013 performed in the Fukuoka prefecture at station F1.

Table 1. The details of the observations made by the coastal prefectures in the Ariake Sea.

\begin{tabular}{cccc}
\hline Prefecture & Period & The number of stations & The number of parameters \\
\hline Fukuoka & $1997-2013$ & 10 & 14 \\
Saga & $1972-2013$ & 14 & 14 \\
Kumamoto & $1974-2013$ & 22 & 14 \\
\hline
\end{tabular}

\subsection{Principal Component Analysis}

Since enormous quantities of data related to water quality of the Ariake Sea have been collected, extracting the environmental characteristics would seem easy. However, as can be seen in Figure 2 and Table 1, most of the data is raw and it is very difficult to understand the environmental conditions or historical changes with this data. Multidimensional data analysis methods are very useful when large quantities of data need to be analysed for a target area.

PCA can provide information on the most meaningful parameters that aid data set interpretation, data reduction, and summarize the statistical correlation among constituents in the water with minimal loss of original in- 
formation [9] [15]. The first principal component loading represents most of the variance in the observed variables, while each subsequence component explains progressively less variance [16]. PCA is used for understanding the characteristics of water qualities in many fields [17] [18], and it has provided important information for environment improvement.

In this study, PCA was performed for the 11 variables, mentioned above, at the sampling stations in the Fukuoka, Saga, and Kumamoto prefectures from 1998 to 2013, in order to identify important water quality parameters. The 11 variables are dissolved oxygen (DO), chemical oxygen demand (COD), dissolved inorganic nitrogen (DIN), ammonium-nitrogen $\left(\mathrm{NH}_{4}^{+}-\mathrm{N}\right)$, nitrate-nitrogen $\left(\mathrm{NO}_{3}^{-}-\mathrm{N}\right)$, nitrite-nitrogen $\left(\mathrm{NO}_{2}^{-}-\mathrm{N}\right)$, phosphate-phosphorus ( $\left.\mathrm{PO}_{4}^{3-}-\mathrm{P}\right)$, and silica (Si). Table 2 shows the details of the water quality parameters.

\section{Results and Discussions}

Table 3 shows the correlation coefficient of eleven water quality parameters used in the analysis. Salinity had high negative correlation with each nutrient except $\mathrm{NH}_{4}$. The nutrients also had high correlations with each other. This means that most of the nutrients, with the exception of $\mathrm{NH}_{4}-\mathrm{N}$, originate from rivers. DO and COD had high negative correlation (-0.923). This means that DO are consumed during the decomposition of organic matter in the sea. Moreover, it can be said that the amount of DO is insufficient for decomposing organic matter.

Table 2. Symbol, units, mean value, and standard deviation of the physic-chemical parameters determined in each survey.

\begin{tabular}{ccccc}
\hline Parameters & Symbol & Unit & Mean & Standard Deviation \\
\hline Transparency & $\mathrm{Tr}$ & $\mathrm{M}$ & 2.855 & 2.439 \\
Water Temperature & $\mathrm{T}$ & ${ }^{\circ} \mathrm{C}$ & 18.714 & 6.284 \\
Salinity & $\mathrm{S}$ & $\mathrm{Psu}$ & 29.259 & 4.547 \\
Dissolved Oxygen & $\mathrm{DO}$ & $\mathrm{mg} / \mathrm{L}$ & 5.057 & 3.126 \\
Chemical Oxygen Demand & $\mathrm{COD}$ & $\mathrm{mg} / \mathrm{L}$ & 4.278 & 3.651 \\
Dissolved Inorganic Nitrogen & $\mathrm{DIN}$ & $\mathrm{mg} / \mathrm{L}$ & 8.020 & 10.790 \\
Ammonium-Nitrogen & $\mathrm{NH}_{4}$ & $\mu \mathrm{g}-\mathrm{at} / \mathrm{L}$ & 1.923 & 2.584 \\
Nitrate-Nitrogen & $\mathrm{NO}_{3}$ & $\mu \mathrm{g}-\mathrm{at} / \mathrm{L}$ & 5.106 & 8.344 \\
Nitrite-Nitrogen & $\mathrm{NO}_{2}$ & $\mu \mathrm{g}-\mathrm{at} / \mathrm{L}$ & 0.992 & 1.193 \\
Phosphate-Phosphorus & $\mathrm{PO}_{4}$ & $\mu \mathrm{g}-\mathrm{at} / \mathrm{L}$ & 0.669 & 0.618 \\
Silica & $\mathrm{Si}$ & $\mu \mathrm{g}-\mathrm{at} / \mathrm{L}$ & 47.015 & 40.335 \\
\hline
\end{tabular}

Table 3. Correlation matrix of the 11 physico-chemical parameters.

\begin{tabular}{|c|c|c|c|c|c|c|c|c|c|c|c|}
\hline & $\operatorname{Tr}$ & $\mathrm{T}$ & S & DO & COD & DIN & $\mathrm{NO}_{3}$ & $\mathrm{NO}_{2}$ & $\mathrm{NH}_{4}$ & $\mathrm{PO}_{4}$ & $\mathrm{Si}$ \\
\hline $\operatorname{Tr}$ & 1.000 & & & & & & & & & & \\
\hline $\mathrm{T}$ & -0.031 & 1.000 & & & & & & & & & \\
\hline S & 0.377 & -0.345 & 1.000 & & & & & & & & \\
\hline DO & 0.379 & -0.091 & 0.170 & 1.000 & & & & & & & \\
\hline COD & -0.452 & -0.042 & -0.220 & -0.923 & 1.000 & & & & & & \\
\hline DIN & -0.314 & 0.099 & -0.670 & -0.148 & 0.147 & 1.000 & & & & & \\
\hline $\mathrm{NO}_{3}$ & -0.309 & 0.140 & -0.505 & -0.111 & 0.110 & 0.772 & 1.000 & & & & \\
\hline $\mathrm{NO}_{2}$ & -0.278 & 0.057 & -0.679 & -0.135 & 0.144 & 0.977 & 0.642 & 1.000 & & & \\
\hline $\mathrm{NH}_{4}$ & -0.222 & 0.198 & -0.219 & -0.154 & 0.079 & 0.540 & 0.333 & 0.452 & 1.000 & & \\
\hline $\mathrm{PO}_{4}$ & -0.380 & 0.220 & -0.413 & -0.254 & 0.239 & 0.725 & 0.645 & 0.652 & 0.602 & 1.000 & \\
\hline $\mathrm{Si}$ & -0.468 & 0.334 & -0.762 & -0.179 & 0.232 & 0.742 & 0.632 & 0.709 & 0.383 & 0.681 & 1.000 \\
\hline
\end{tabular}


Table 4 summarizes the PCA results, including the loadings and eigenvalues of each principal component (PCs); the total variance and strong loading values are highlighted. The results show three PCs, which explained $74.4 \%$ of the total variance. The first PC explained $46.8 \%$ of the total variance and was best represented by DIN, $\mathrm{Si}, \mathrm{NO}_{2}, \mathrm{PO}_{4}, \mathrm{NO}_{3}$, and salinity. The second PC was dominated by $\mathrm{DO}$ and $\mathrm{COD}$, accounting for $17.7 \%$ of the total variance. The third PC explained $9.9 \%$ of the total variance and loaded heavily on temperature.

As can be seen in Table 2, PC 1 is related mostly with the nutrients with positive and negative values of salinity. Thus, it can be said that PC 1 explains the nutrient amounts that originate from rivers. PC 2 represents the organic pollution, since it was represented primarily by DO and COD. Given that the third PC was mainly represented by temperature, PC 3 represents the seasonal change.

Figure 3 displays the scores for PC 1 at the six stations F4, F7, S1, S3, K1, and K14 (Figure 1). According to PC 1, which represents the nutrient amount originating from rivers, the amount of nutrients is higher in summer to fall and lower in winter to spring. Moreover, the nutrient amounts of the inner bay (F4, F7, S1, and S14) are higher than that of the bay month (K1) and center (K14). At station F7, the scores showed the highest value and widest variation. This reveals that the environment of the Ariake Sea is strongly influenced by riverine nutrients, especially from the Chikugo River. Figure 4 shows the time series of the PC 2 scores at six stations. The results of PC 2, which represent the organic pollution level, showed an opposite trend from the ones shown by PC 1;

Table 4. Loadings of the 11 physico-chemical variables for three significant principal components of all survey results.

\begin{tabular}{cccc}
\hline Variable & PC 1 & PC 2 & PC 3 \\
\hline $\mathrm{Tr}$ & -0.235 & -0.307 & 0.024 \\
$\mathrm{~T}$ & 0.120 & -0.080 & 0.882 \\
$\mathrm{~S}$ & -0.335 & 0.057 & -0.262 \\
$\mathrm{DO}$ & -0.157 & -0.625 & -0.050 \\
$\mathrm{COD}$ & 0.161 & 0.642 & -0.043 \\
$\mathrm{DIN}$ & 0.404 & -0.173 & -0.210 \\
$\mathrm{NO}_{3}$ & 0.340 & -0.149 & -0.136 \\
$\mathrm{NO}_{2}$ & 0.381 & -0.165 & -0.222 \\
$\mathrm{NH}_{4}$ & 0.254 & -0.085 & -0.054 \\
$\mathrm{PO}_{4}$ & 0.363 & -0.040 & -0.070 \\
$\mathrm{Si}$ & 0.385 & -0.068 & 0.171 \\
Eigenvalue & 5.15 & 1.948 & 1.084 \\
Cumulative variance (\%) & 46.8 & 17.7 & 9.86
\end{tabular}

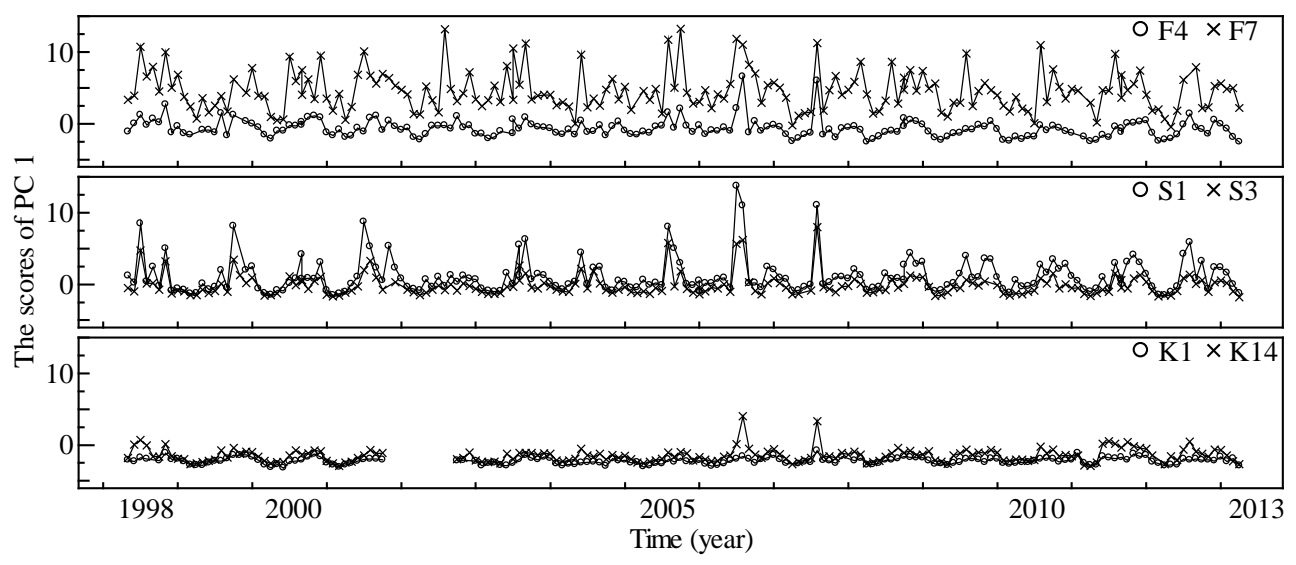

Figure 3. The time series of the scores for PC 1 at 6 stations (F4, F7, S1, S3, K1, and K14). 
there were low levels during summer to autumn and high levels for winter to spring. The variation in PC 2 showed similar behavior to PC 1, meaning it was high in the inner bay (F4, F7, K1, and K14). For the inner bay trends, the scores for the Fukuoka area (F4 and F7) were lower than that of the Saga area (S1 and S3). This means that the organic pollution is progressing only in the Saga (north-west) section of the Ariake Sea. Figure 5 displays the scores for PC 3 at six stations. According to Figure 3, the variation in PC 3 is higher in the inner bay (F4, F7, S1, and S3) with distinctive changes observed over the past three years (2010 to 2013).

Figure 6 shows the scatter diagram of the PC 1 and 2 scores over the entire time period. Most of the points of the Fukuoka area are distributed in the fourth quadrant where the amount of nutrients inputs from the river is high but the organic pollution level is low. In contrast, the points for the Saga area are distributed in the first quadrant where both the amount of nutrients inputs from the river and level of organic pollution are high. The points for the Kumamoto area are frequently seen in the third quadrant; here the nutrient concentration and organic pollution levels are low.

As discussed, despite the high amount of nutrients from the river in both the Fukuoka and Saga areas, the organic pollution level had different results in each area. This could be explained by the tidal residual flow in the inner bay of the Ariake Sea. According to previous research [19], tidal residual flow in the Ariake Sea circulates in an anticlockwise direction. Thus, tidal currents enter from the bay mouth and travel through the northeast, the northwest, Isahaya Bay, and back to the entrance. The biggest river, Chikugo River, is located in northeast part of the Ariake Sea. The Chikugo River accounts for $50 \%$ of all inflow into the Ariake Sea, and therefore, has a strong influence on the environment. The nutrients from the Chikugo River spread over the inner bay because of the tidal flow. Subsequently, internal production processes use these nutrients up, which results in organic pollution. Due to the anticlockwise tidal residual flow, the nutrients or organic matter finally flow into northwest area. Consequently, the organic pollution level in the northwest area is much higher than in the northeast area.

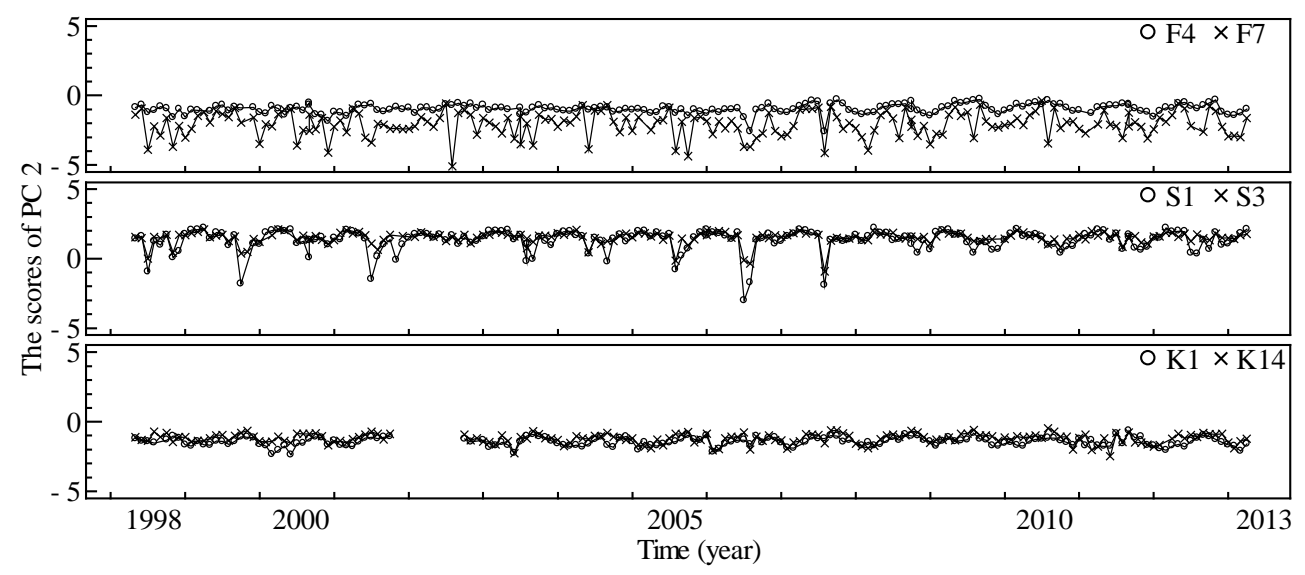

Figure 4. The time series of the scores for PC 2 at 6 stations (F4, F7, S1, S3, K1, and K14).

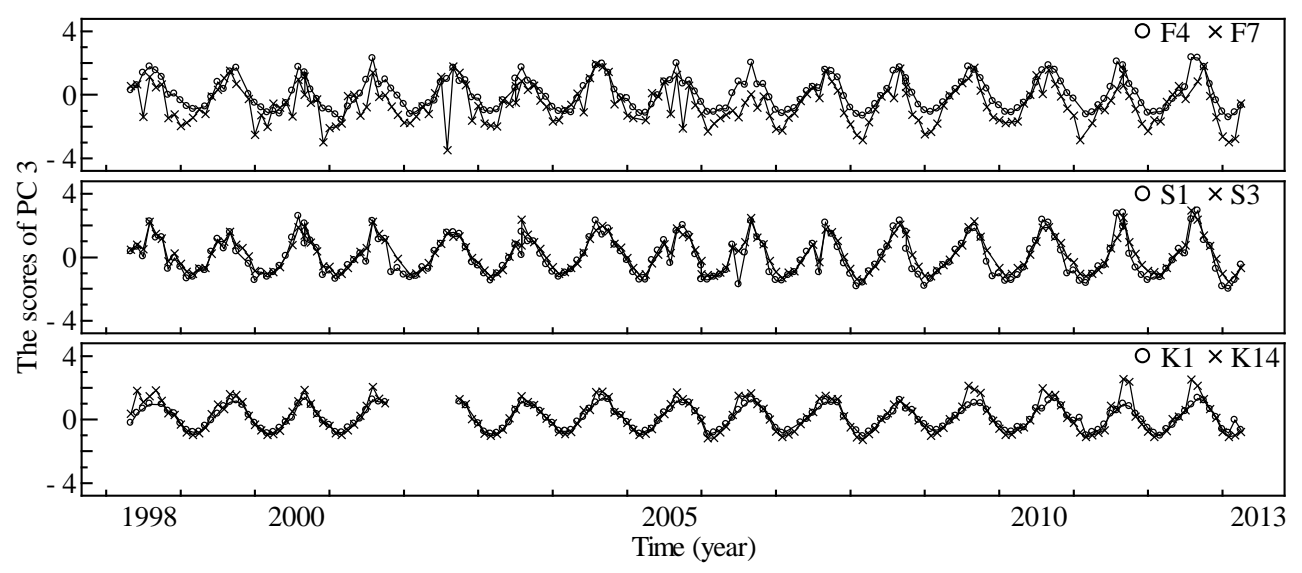

Figure 5. The time series of the scores for PC 3 at 6 stations (F4, F7, S1, S3, K1, and K14). 


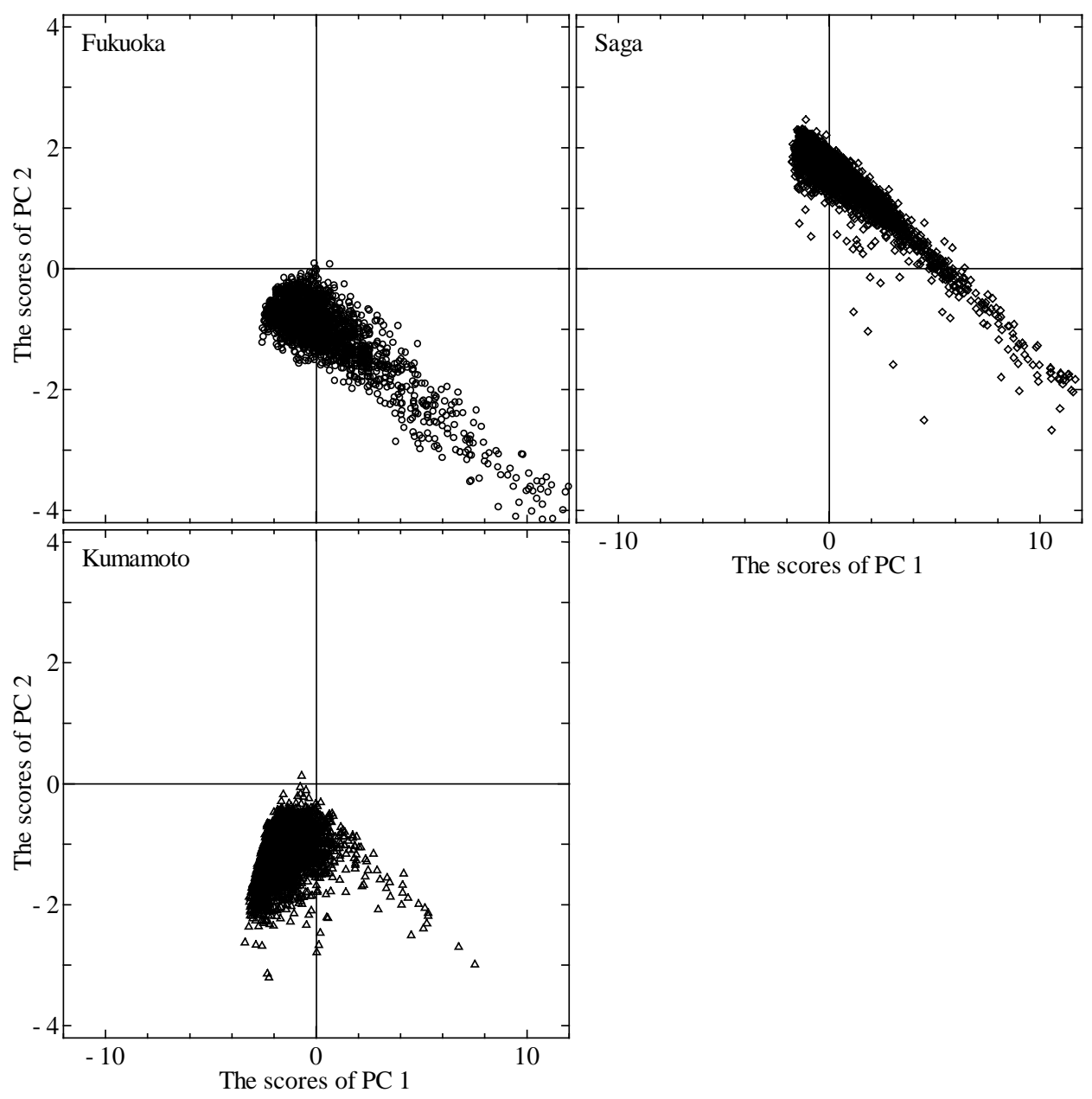

Figure 6. Scatter diagrams of PC 1 and PC 2 scores of all station in all period.

\section{Conclusion}

In this study, PCA was used to investigate the environmental condition of the Ariake Sea with eleven water quality parameters surveyed from the coastal prefectures. PCA provided three meaningful components, which were the amount of nutrients originating from rivers, organic pollutant levels, and seasonal changes. In conclusion, the two main factors that influence the coastal environment in this sea are the nutrient inflow from rivers, especially from the Chikugo River, and the anticlockwise tidal residual flow in the Ariake Sea. Therefore, in order to improve the environmental condition of this area, these two factors must be considered.

\section{Acknowledgements}

The authors wish to thank the Ariakekai Laboratory of Fukuoka Fisheries and MarineTechnology Research Center, the Saga Prefectural Ariake Fisheries Research and Development Center, and finally, the Kumamoto Prefectural Fisheries Research Center for providing data on the Ariake Sea. This research was partially supported by the FY2012-2014 JSPS Core-to-Core Program (B. Asia-Africa Science Platforms), and JSPS KAKENHI Grant Numbers 23380144 and 241526.

\section{References}

[1] Hamada, K., Hayami, Y., Yamamoto, K., Ohgushi, K., Yoshino, K., Hirakawa, R. and Yamada, Y. (2008) Serious Hypoxia in the Head of the Ariake Sea in Summer, 2006. Oceanography Society in Japan, 17, 371-377.

[2] Kajihara, Y., Tomita, T., Nakano, T. and Isobe, M. (2003) Occurrence of Hypoxic Water in the Inner Area of Ariake 
Bay in the Summer of 2002. Journal of the Japan Society of Civil Engineers, 747, 187-196.

[3] Tsutsumi, H., Tsutsumi, A., Takamatsu, A., Kimura, C., Nagata, S., Tsukuda, M., Komorita, T., Takahashi, T. and Montani, S. (2007) Mechanisms for the Expansion of Hypoxic Water in the Inner Areas of Ariake Bay during Summer. Oceanography in Japan, 16, 182-202.

[4] Shutou, T., Matsubara, T. and Kuno, K. (2009) Nutrient State and Nori Aquaculture in Ariake Bay. Aquabiology, 31, 168-170.

[5] Nakane, T. (2013) Annual Change of Fishery Production in Ariake Bay. Aquabiology, 35, 447-456.

[6] Tsutsumi, H. (2012) Mechanism and Causes of Large-Scale Red Tides in the Inner Part of Ariake Bay. Bulletin on Coastal Oceanography, 49, 165-174.

[7] Isobe, M. and Koibuchi, Y. (2004) Continuous Measurement of the Water Environment in the Ariake Bay. Bulletin on Coastal Oceanography, 42, 27-33.

[8] Tabata, T., Hiramatsu, K., Harada, M. and Hirose, M. (2013) Numerical Analysis of Convective Dispersion of Pen Shell Atrina pectinata Larvae to Support Seabed Restoration and Resource Recovery in the Ariake Sea, Japan. Ecological Engineering, 57, 154-161. http://dx.doi.org/10.1016/j.ecoleng.2013.04.018

[9] Mizumukai, K., Sato, T., Tabeta, S. and Kitazawa, D. (2008) Numerical Studied on Ecological Effects of Artificial Mixing of Surface and Bottom Waters in Density Stratification in Semi-Enclosed Bay and Open Sea. Ecological Modelling, 214, 251-270. http://dx.doi.org/10.1016/j.ecolmodel.2008.02.023

[10] Shiratani, E., Kiri, H., Takaki, K., Hamada, K., Tanji, H. and Nakata, K. (2007) Research on Factors of Tide and Tidal Current Changes in the Ariake Sea, Irrigation. Drainage and Rural Engineering Journal, 252, 145-156.

[11] Vega, M., Pardo, R., Barrado, E. and Deban, L. (1998) Assessment of Seasonal and Polluting Effects on the Quality of River Water by Exploratory Data Analysis. Water Research, 32, 3581-3592. http://dx.doi.org/10.1016/S0043-1354(98)00138-9

[12] Helena, B., Pardo, R., Vega, M., Barrado, E., Fernandez, J.M. and Fernandez, R. (2000) Temporal Evolution of Groundwater Composition in an Alluvial Aquifer (Pisuerga River, Spain) by Principal Component Analysis. Water Research, 34, 807-816. http://dx.doi.org/10.1016/S0043-1354(99)00225-0

[13] Simenov, V., Stratis, J.A., Samara, C., Zachariadis, G., Voutsa, D., Anthemidis, A., Sofoniou, M. and Kouimtzis, T. (2003) Assessment of the Surface Water Quality in Northern Greece. Water Research, 37, 4119-4124. http://dx.doi.org/10.1016/S0043-1354(03)00398-1

[14] Inoue, N. (1980) Physical Environments (Oceanographic Description of the Coast of Japan XIX: Ariake Bay (II)). Bulletin on Coastal Oceanography, 17, 151-165.

[15] Wunderlin, D.A., Diaz, M.P., Ame, M.V., Pesce, S.F., Hued, A.C. and Bistoni, M.A. (2001) Pattern Recognition Techniques for the Evaluation of Spatial and Temporal Variations in Water Quality. A Case Study: Suquia River Basin (Cordoba-Argentina). Water Research, 35, 2881-2894. http://dx.doi.org/10.1016/S0043-1354(00)00592-3

[16] Chen, K., Jiao, J.K., Huang, J. and Huang, R. (2007) Multivariate Statistical Evaluation of Trace Elements in Groundwater in a Coastal Area in Shenzhen, China. Environmental Pollution, 147, 771-780. http://dx.doi.org/10.1016/j.envpol.2006.09.002

[17] Oketola, A.A., Adekolurejo, S.M. and Osibanjo, O. (2013) Water Quality Assessment of River Ogun Using Multivariate Statistical Techniques. Journal of Environmental Protection, 4, 466-479. http://dx.doi.org/10.4236/jep.2013.45055

[18] Harada, M. and Yoshida, I. (2001) Distribution of Sulfides and Heavy Metals of Bottom Sediments in Lake Koyama. Transactions of Rural Planning, 3, 64-66.

[19] Tanaka, M., Inagaki, S. and Yamaki, K. (2002) Numerical Simulation of Tide and Three Dimensional Flow in Ariake Bay. Proceedings of Coastal Engineering, 49, 406-410. 
Scientific Research Publishing (SCIRP) is one of the largest Open Access journal publishers. It is currently publishing more than 200 open access, online, peer-reviewed journals covering a wide range of academic disciplines. SCIRP serves the worldwide academic communities and contributes to the progress and application of science with its publication.

Other selected journals from SCIRP are listed as below. Submit your manuscript to us via either submit@scirp.org or Online Submission Portal.
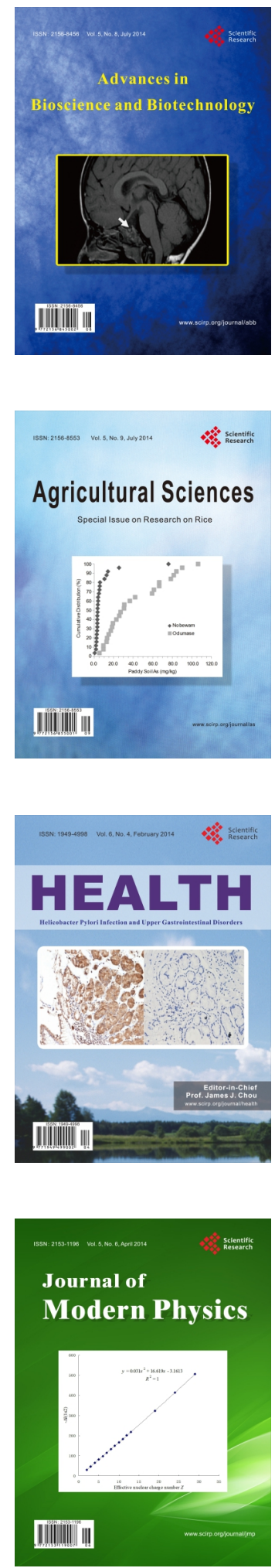
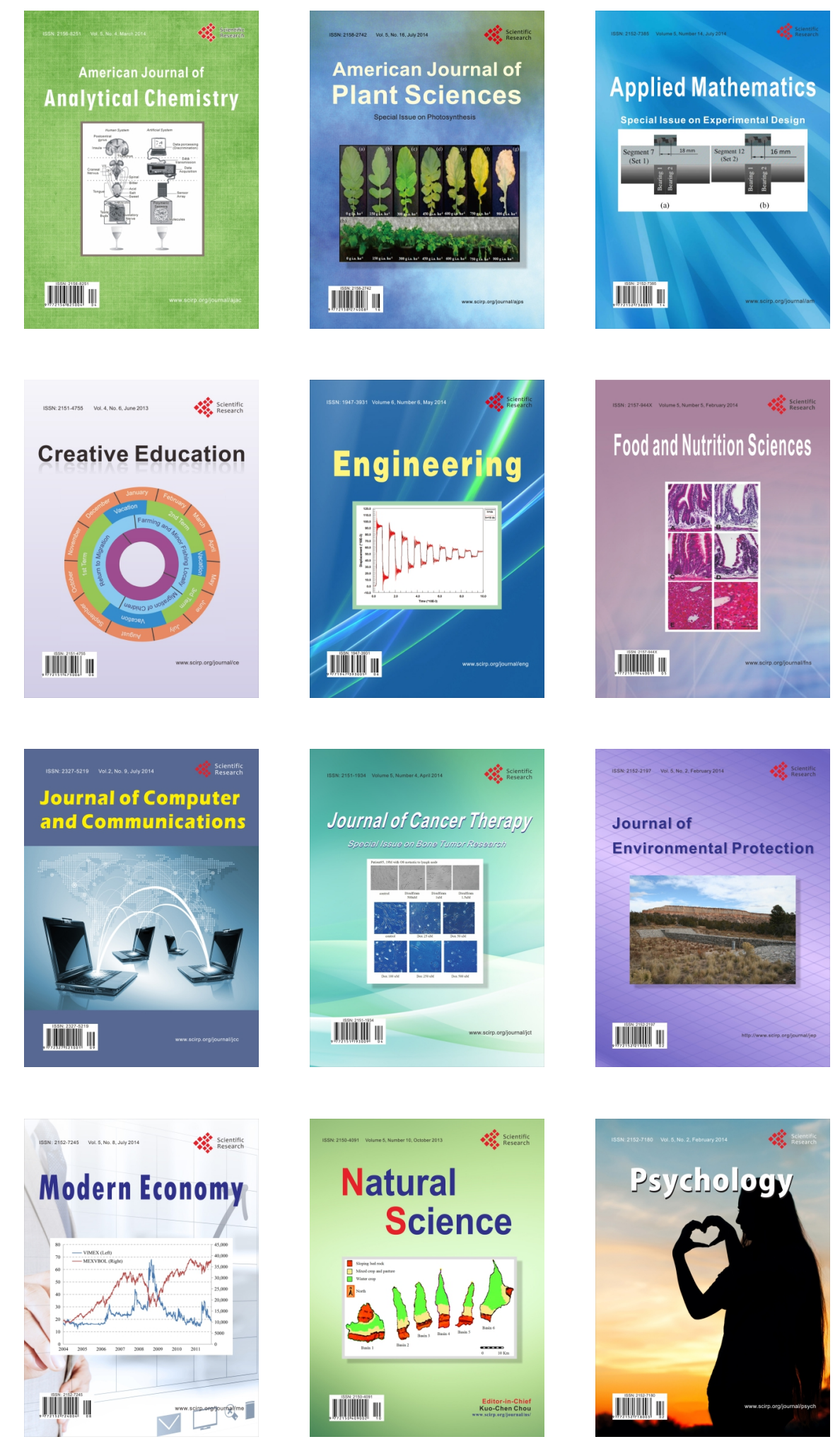